cytosis (20,000 or more) have been operated on at various ages and remained well afterward. Several such patients operated on by us were previously diagnosed as having true leukemia, and were treated for it.

With the splenic anemias may be classified Gaucher's disease, which is shown by Brill and Mandelbaum ${ }^{20}$ to appear before the thirteenth year and average twenty-five years of duration, and the patient usually dies from some complication. The spleen may become of enormous size. In the terminal stages of Gaucher's disease or large cell splenomegalia, endothelial growths of the same character are found in the liver, lymphatics, etc. Our experience in the removal of the spleen in three cases of this kind has shown that in the earlier stages the condition is cured by splenectomy (Fig. 5).

One of the most interesting anemias of splenic origin is the so-called hemolytic jaundice, a disease of the young, accompanied by acholuric jaundice, that is, there is no evidence of biliary obstruction, bile is present in the stools and there is no itching. There are two types of this disease, one the familial type of Minkowski, ${ }^{21}$ which often affects several members of the same family and is less severe in its manifestations, many patients living out a life expectancy. The other is the acquired type of Hayem $^{22}$ and Widal, ${ }^{15}$ which comes on during puberty or adolescence and usually ends in death. In hemolytic jaundice the patient suffers from crises accompanied by tenderness over the liver and spleen, an increase of temperature and quickness of pulse. We have done nine splenectomies for hemolytic jaundice. No other operation I know of gives more brilliant and striking results. Within twenty-four hours the jaundice begins to disappear, and in a few days the patients perhaps for the first time have clear complexions; the anemia is rapidly overcome and they remain well (Fig. 6).

Pernicious Anemia: Eppinger first called attention to the remarkable improvement of the patient after removal of the spleen in pernicious anemia. Although sufficient time has not elapsed to say that these patients are permanently cured, as Cabot ${ }^{23}$ has said, no other means of therapy has so promptly brought about an improvement in the condition of the patient and so definitely relieved the anemia. It is true that in the late stages when there are spinal cord changes these changes do not disappear, although the condition is marvelously improved, nor do all the characteristic cells of pernicious anemia disappear from the blood. But from our experience with nineteen patients, I feel

20. Brill, N. E., and Mandelbaum, F. S.: Large-Cell Splenomegaly (Gaucher's Disease): A Clinical and Pathological Study, Am. Jour. Med. Sc., 1913, cxlvi, 863 .

21. Minkowski, O.: Ueber eine Hereditäre, unter dem Bilde eines 21. Minkowski, O.: Ueber eine Hereditäre, unter dem Bilde eines
chronischen Icterus mit Urobilinurie, Splenomegalie und Nierensiderosis chronischen Icterus mit Urobilinurie, Splenomegalie und Nierensiderosis
verlaufenden Affection, Verhandl. d. Kong. f. inn. Med., 1900, xviii, 316. 22. Hayem, G.: Sur un variété particulière d'ictère chronique, ictère infectieux chronique spléno-mégalique, Presse méd., 1898, i, 121; Nouvelle contribution à l'étude de l'ictère infectieux chronique splénomégalique, Bull. et mém. Soc. méd. d. hôp. de Paris, 1908, Series ? $\mathrm{xxv}, 122$

23. Cabot, R. C.: Discussion on Blood and Blood Diseases, abstr. The Journal A. M. A., June 26, 1915, p. 2164 . justified in performing splenectomy in selected cases of pernicious anemia, and have at least the hope that if it is done sufficiently early in the course of the disease, it will permanently check if not cure the condition (Fig. 7).

Preliminary to splenectomy and, in some cases, following it, transfusion of blood may be necessary. The blood of the donor should always be tested in connection with the recipient for agglutination and hemolysis.

\section{CAUTERIZATION AND FULGURATION OF BLADDER TUMORS}
HOWARD A. KELLY, M.D.
AND

WILLIAM NEILL, M.D.

BALTIMORE

The past ten years have witnessed a remarkable and beneficent change in the treatment of benign neoplasms of the bladder. Fulguration has become by common consent the method of choice for all cases in which it can be applied. The credit for this remarkable advance in vesical surgery lies at the door of Dr. Edwin Beer, ${ }^{1}$ who has made this new field peculiarly his own, both by discovery and by development.

Beer's pioneer work has thus wrought a most welcome transformation in what was previously often a perplexing situation. He has reduced the complex to the category of the simple, always a notable surgical achievement, so that now instead of putting these patients to bed and exposing them to the risks and discomforts of an operation, we treat them as ambulatory office patients and destroy the growth often in from one to several sittings.

In cases of recurrence the greatest benefits of the new plan are realized, for here the patient continues the treatment at intervals and without discomfort, until the entire trouble is finally eradicated to return no more. Under former conditions a recurrence simply meant an outlook for another operation and a siege in the hospital.

Here are two illustrative cases from personal experiences:

Case 1 (Hosp. No. 5480).--Miss M. G., aged 41, had been operated on twice before for papilloma of the bladder, the first time by Dr. Harris of Battle Creek, Sept. 26, 1911, and again for a recurrence by another operator, Aug. 28, 1912, the suprapubic route being taken both times. Six months later she was examined by two surgeons in Brooklyn, and a return of the trouble was found. Both surgeons advised the use of the high frequency current. Treatment by Roentgen

1. Beer, Edwin: Removal of Neoplasms of the Urinary Bladder, THE Journal A. M. A., May 28, 1910, p. 1768; The Treatment of Papillary Tumors of the Urinary Bladder with the High Frequency Current (Oudin), ibid., Nov. 16, 1912, p. 1785; Ann. Surg., August, 1911; Treatment of Benign Papillomata of the Urinary Bladder with High Frequency Current, Ann. Surg., June, 1915, 1xi, 109; ibid., 1xii, 496; Treatment of Benign Papillomata of the Urinary Bladder with the Oudin High Frequency Current Introduced through a Catheterizing Cystoscope, Med. Rec., New York, Feb. 8, 1913. 
ray had also been used. When first seen by Dr. Kelly she was examined through the open cystoscope, May 29, 1914, and the following condition noted:

Along the posterior wall half way from the vertex to the base of the bladder was a transverse area of ulceration, 26 $\mathrm{mm}$. broad. A similar area was seen in the vertex, $18 \mathrm{~mm}$. in diameter; directly opposite the internal ureteral orifice on the posterior wall was a papillomatous growth, $1 \mathrm{~cm}$. in

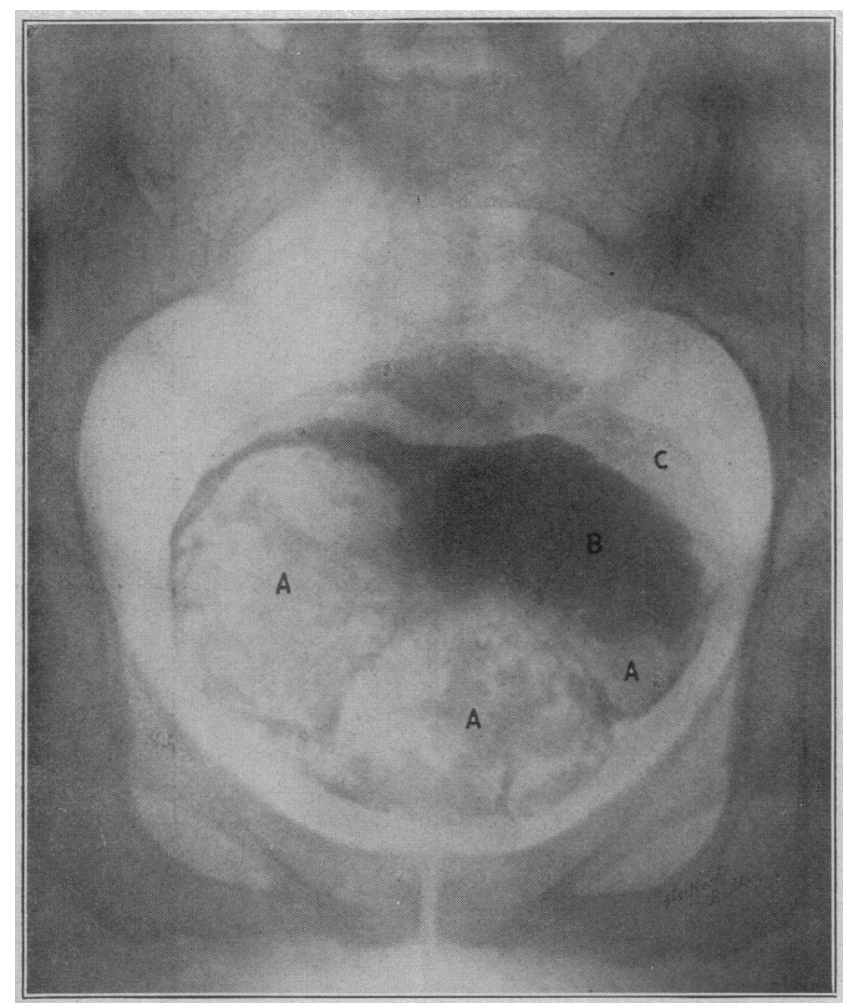

Fig. 1.-Bladder in Case 2: $A$, conglomerate mass of large growths: $B$, injected bismuth in suspension; $C$, zone of urine, water and air with the bladder wall in the periphery.

diameter. A similar one grew just to the left of this, from 6 to $8 \mathrm{~mm}$. in diameter. These growths were fulgurated through the open cystoscope. Since that date the patient has returned to the hospital at intervals of from one to two months, and numerous small tumors have been detected sprouting in various locations and treated by fulguration. The treatments were given May 29, June 29, Aug. 17, Sept. 28 and Dec. 24, 1914, and Jan. 7, Jan. 28, Feb. 18, April 2, June 4, June 18, Aug. 5, Sept. 3 and Dec. 17, 1915.

When last treated, Dec. 17, 1915, the bladder was found to be entirely normal except for two small superficial spots about 4 and $2 \mathrm{~mm}$. in diameter above the right ureteral orifice. These were fulgurated for a few seconds, and the patient was told to return in several months for another examination.

This patient is a monument to fulguration, for she never could have survived the numerous operations she would have needed to remove all these recurring growths.

Let us here note an exception to this desideratum of treating all cases by fulguration. When the tumors are massive and there are numerous implantations, it is often preferable to make a suprapubic section and extirpate all visible disease, and then to follow up the case by fulguration if there is any recurrence. Here is a case in point :

Case 2 (Hosp. No. 4079).-Miss B., aged 38, first seen May 8, 1912, complained of passing blood in the urine for eight years. An aeroscopic examination through a Kelly cystoscope showed a large papillomatous tumor attached to the anterior wall of the bladder and seemingly filling it. An examination by Roentgen ray with a moderate bismuth injection of the bladder was made (Fig. 1). Here we have an astonishing picture: the area $A$ represents a conglomerate mass of large growths and shows beautifully their papillomatous nature. About the tumor lies the dark zone $B$, which represents the injected bismuth in suspension. Around this the gray area $C$ is the zone of the urine, water and air with the bladder wall in the periphery.

Dr. Kelly operated in May, 1912, through a suprapubic incision. A small growth, $1.5 \mathrm{~cm}$. in diameter, was found attached to the posterior wall; three large cauliflower growths the size of hen's eggs lay on the anterior wall of the bladder; one of them grew from the trigonum beneath the urethra and between it and the left ureteral orifice, and then encircled and extended down the urethra a short distance; another lay on the anterior wall above the ureteral orifice. These were removed; in all, nine tumors being taken out. The patient made an uneventful recovery and was discharged June 15 , 1912, and remained well and free from all her old symptoms until March 6, 1914, when she had vesical pain, and bleeding on one occasion. An aeroscopic examination, April 6, 1914 showed a recurrence the size of a cherry near the left ureteral orifice; this was fulgurated, and there has been no return of symptoms to date.

There is a borderline between cases which are manifestly best for fulguration, and this small group which we are still inclined to reserve for surgery, where surgeons will discuss their choice of method, one operating, while another prefers the high frequency current; but there is, we believe, a group of massive tumors at present beyond the border where operation is best in competent surgical hands.

We believe that the open aerocystoscope (Kelly's), presents incontestible advantages for seeing these growths, and determining their number and relations, and above all in most cases in enabling the stargeon to see and to handle the pedicle.

A growth which appears sessile and malignant by the water cystoscope may thus be found by the air cystoscope to be pedunculate. We believe that the facility

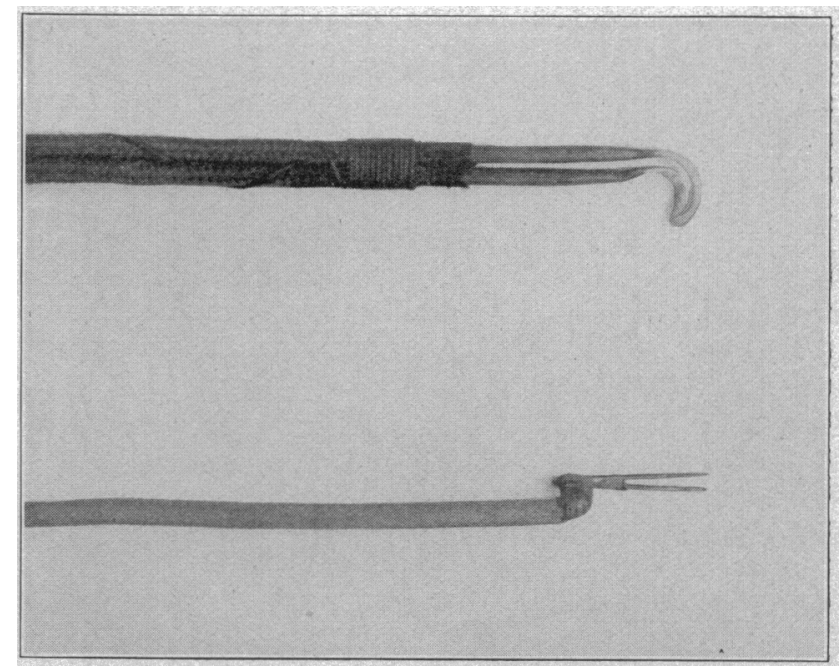

Fig. 2.-Cautery knife and two point fulgurator, natural size.

of exposure and treatment through the open cystoscope (Nos. 10 to 12 ) enables one also greatly to shorten the period of treatment in attacking the pedicle, rather than the peripheral parts which are more accessible. The difference in methods is sometimes comparable to the difference, on the one hand, in taking down a tree by lopping off its branches one by one in the effort to reach the trunk, and on the other of cutting off the 
trunk at once near the roots. We therefore in all cases proceed at once to attack the pedicle and to fulgurate as deeply as possible into its substance. Even large tumors can be handled by fulguration if the pedicle can be reached, and in this way the many sittings are cut down to only a few.

We have found that two slightly diverging needles (Fig. 2) are valuable for fulguration. They are plunged into the substance of the pedicle and the current turned on as strong as the patient can stand it. The pedicle becomes blanched and a large area of necrosis is established, with a correspondingly wide area of consecutive destruction in the periphery. Slender pedicles wither at once, and small sessile growths are eradicated in a few seconds.

By the open cystoscope we are also able to use in an admirable manner and with great effect platinum cautery knives, formerly so much used in throat work to burn and destroy new growths. We figure one here devised to take the place of the plain cautery knife (Fig. 2). This knife, which is sickle-shaped, is hooked around the pedicle, when the cautery current is turned on, heating the blade to a cherry red. By drawing the blade toward the cystoscope the pedicle is cooked or burned through and cut off gradually in part or in whole, as seems best.

1418 Eutaw Place.

\section{PRECORDIAL PAINS OF CARDIOVASCU- LAR AND EXTRACARDIAC ORIGIN}

CLINICAL VARIE'TIES, ETIOLOGY AND THERAPY *

\section{SELIAN NEUHOF, M.D.}

Visiting Physician, Har Moriah Hospital; Adjunct Attending Physician, Lebanon Hospital

\section{NEW YORK}

As early as 1772, Heberden described angina pectoris. Nothnagel ${ }^{1}$ ascribed it to spasm of the coronaries, with consequent local ischemic and nutritive changes in the musculature, a theory which has profoundly affected the literature of the subject. Huchard ${ }^{2}$ divided angina pectoris into true and false: that produced by effort he called true, that without effort, false angina. Mackenzie ${ }^{3}$ ascribed the fundamental cause of cardiac pains, a term which he prefers to angina, to exhaustion of the cardiac musculature. Osler ${ }^{4}$ described four types of angina pectoris: the reflex, neurasthenic, hysterical and the Nothnagel.

The frequent indiscriminate use of such terms as "false angina pectoris," "angina sine dolore," "angina vasomotoria," "angina vera," etc., with no clear sense of their etiology or pathology, has added to the difficulty of comprehending the fundamental causes of precordial pains. This symptomatic and pathologic confusion, and the fact that precordial pains of similar distribution and character may be caused both by intracardiac and extracardiac disease, have stimulated me to make a careful study of those patients in whom these pains, from whatever cause, were the only or the most prominent symptoms. In every case a very careful history, the importance of which is often overlooked, was obtained. Besides the routine, the clinical exami-

* Read before the Bronx County Medical Society, Feb. 16, 1916, and in part before the New York County Medical Society, Nov. 22, 1915. 1. Nothnagel: Deutsch. Arch. f. klin. Med, 1867, v, 3 .

2. Huchard: Diseases of the Heart, 1910, p. 50.

3. Mackenzie: Diseases of the Heart, 1913, p. 72.

4. Osler and McCrae: System of Medicine, iv, 449 nation often inciuded phenolsulphonephthalein and sodium chlorid excretion tests, and electrocardiographic and orthodiascopic tracings. The type, character, intensity and distribution of the pain, the time of its appearance, its correlation with exercise, with digestive or other disturbances, and the presence or absence of Head's zones were noted. After study of all data, an attempt was made to discover the probable fundamental etiologic lesion in the cardiovascula: system (the myocardium, endocardium, kidneys or arteries), or in a distant organ (usually the gastrointestinal canal), and to gage the extent and severity of the pathologic damage to be therapeutically attacked. In this manner, besides obtaining a rational view of the entire subject, one could fairly definitely pick out and group patients in whom therapy would be of no avail, as well as those in whom it perhaps offered good chances for relief and even symptomatic cure.

Studies of the cardiovascular nerve supply have shown that there are rich ganglionic and nerve plexuses which surround the heart and the root of the aorta ${ }^{5}$ and are formed by branches of the vagus and sympathetic. There are also ganglionic cells and nerve fibrils in the sino-auricular node, ${ }^{6}$ the auriculoventricular bundle $^{7}$ and throughout the cardiac musculature, ${ }^{8}$ So far as known, nerves of sensation are absent. Through the fundamental work of Sherrington, ${ }^{9}$ Head $^{10}$ and later of Mackenzie, ${ }^{11}$ it is known that a viscus, though not possessed of nerves of sensibility, may, when irritated, excite the corresponding visceral segment of the spinal cord; the latter then sends abnormal centrifugal impulses to the muscles, glands, etc., which in the skin give rise to morbid sensations usually felt and denoted as pains. In cardiac disease, the area ordinarily affected is the precordium; depending on the nerves involved, the intensity of the irritation, or possibly on the irradiation of the centripetal impulse to other spinal segments, the pain may spread to the entire chest, to both arms (especially the left), the fingers, neck, head, the interscapular region, the epigastrium, the abdomen and even the thighs. Besides the precordium and left shoulder, the epigastrium is the favorite site for referred pains, a fact which often causes erroneous diagnoses, and mistakenly directs the therapy to the stomach. In severe cases, the pain is usually sharp, lancinating and agonizing in character, and is combined with the oft described feeling of impending death. In milder cases, it may be dull or aching or there may be a feeling of oppression on the chest. Head's zones are sometimes present, usually over the precordium, more rarely in the epigastrium. Occasionally the pressure even of wearing apparel produces severe pain. The sensitiveness may be confined to the underlying intercostal muscles; deep pressure alone then elicits pain. It is sometimes possible in a general way to judge of the effect of therapy and the progress of the disease by the amount of pain produced on superficial or deep pressure.

In this connection it is important to discuss the frequency of epigastric pains and occasional epigastric Head's zones found in heart disease. These are usually ascribed to an enlarged liver or to congested gastric mucous membrane. However, the pains are

5. Manouélian: Ann. de l'Inst. Pasteur, June, 1914.

6. Oppenheimer, B. S., and Oppenheimer, A.: Jour. Exper. Med.,

1912, xvi, 613.

7. Wilson: Proc. Roy. Soc., 1909, lxxxi, Series B.

8. Kent: Brit. Med. Jour., July 18, 1914.

9. Sherrington: Integrative Action of the Nervous System.

10. Head: Sensebilitaetsstoerungen der Haut, etc., 1898.

11. Mackenzie: Symptoms and Their Interpretations. 